\title{
Ion velocities in direct current arc plasma generated from compound cathodes 211102
}

\author{
Igor Zhirkov, Anders Eriksson and Johanna Rosén
}

\section{Linköping University Post Print}

\section{Tweet}

N.B.: When citing this work, cite the original article.

Original Publication:

Igor Zhirkov, Anders Eriksson and Johanna Rosén, Ion velocities in direct current arc plasma generated from compound cathodes211102, 2013, Journal of Applied Physics, (114), 21, 213302.

http://dx.doi.org/10.1063/1.4841135

Copyright: American Institute of Physics (AIP) http://www.aip.org/

Postprint available at: Linköping University Electronic Press http://urn.kb.se/resolve?urn=urn:nbn:se:liu:diva-103292 


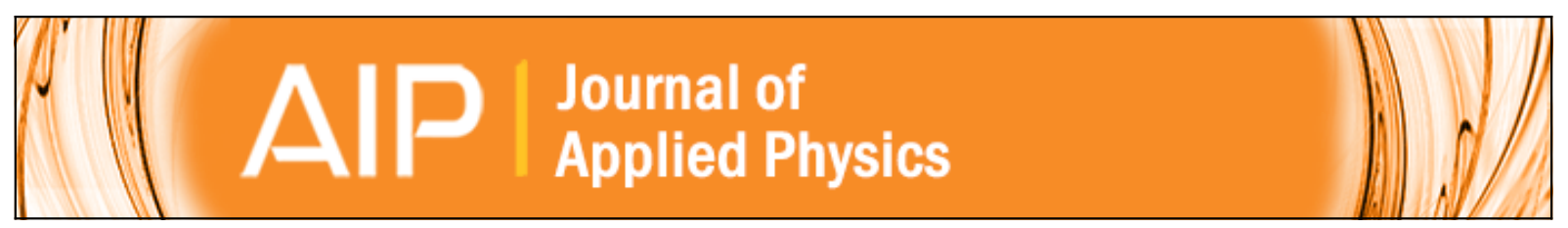

Ion velocities in direct current arc plasma generated from compound cathodes

I. Zhirkov, A. O. Eriksson, and J. Rosen

Citation: Journal of Applied Physics 114, 213302 (2013); doi: 10.1063/1.4841135

View online: http://dx.doi.org/10.1063/1.4841135

View Table of Contents: http://scitation.aip.org/content/aip/journal/jap/114/21?ver=pdfcov

Published by the AIP Publishing

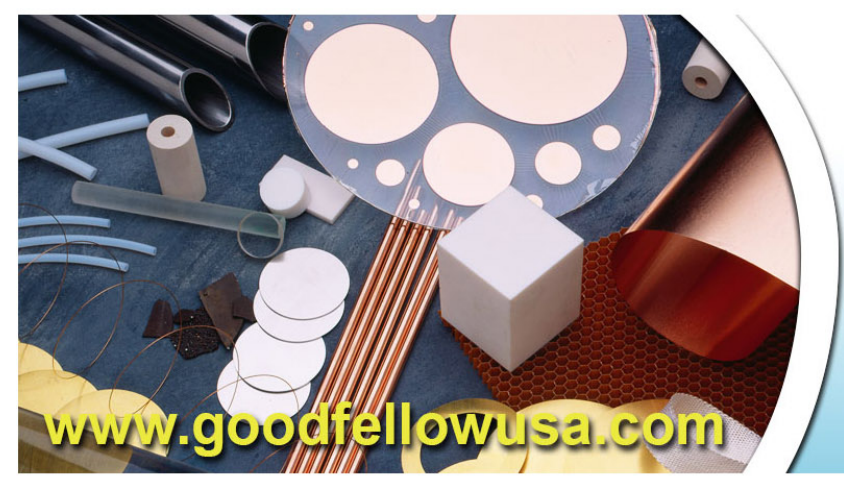

BoOdFEl/OW

metals • ceramics $\cdot$ polymers

composites $\bullet$ compounds • glasses

Save $5 \%$ Buy online 70,000 products $\cdot$ Fast shipping 


\title{
Ion velocities in direct current arc plasma generated from compound cathodes
}

\author{
I. Zhirkov, ${ }^{1, \text { a) }}$ A. O. Eriksson, ${ }^{1,2}$ and J. Rosen ${ }^{1}$ \\ ${ }^{1}$ Thin Film Physics Division, Department of Physics, Chemistry and Biology (IFM), Linköping University, \\ SE-581 83 Linköping, Sweden \\ ${ }^{2}$ Oerlikon Balzers Coating AG, Iramali 18, 9496 Balzers, Liechtenstein
}

(Received 16 September 2013; accepted 20 November 2013; published online 6 December 2013)

\begin{abstract}
Arc plasma from Ti-C, Ti-Al, and Ti-Si cathodes was characterized with respect to charge-stateresolved ion energy. The evaluated peak velocities of different ion species in plasma generated from a compound cathode were found to be equal and independent on ion mass. Therefore, measured difference in kinetic energies can be inferred from the difference in ion mass, with no dependence on ion charge state. The latter is consistent with previous work. These findings can be explained by plasma quasineutrality, ion acceleration by pressure gradients, and electron-ion coupling. Increasing the $\mathrm{C}$ concentration in Ti-C cathodes resulted in increasing average and peak ion energies for all ion species. This effect can be explained by the "cohesive energy rule," where material and phases of higher cohesive energy generally result in increasing energies (velocities). This is also consistent with the here obtained peak velocities around 1.37, 1.42, and $1.55\left(10^{4} \mathrm{~m} / \mathrm{s}\right)$ for ions from $\mathrm{Ti}_{0.84} \mathrm{Al}_{0.16}, \mathrm{Ti}_{0.90} \mathrm{Si}_{0.10}$, and $\mathrm{Ti}_{0.90} \mathrm{C}_{0.10}$ cathodes, respectively. (C) 2013 AIP Publishing LLC. [http://dx.doi.org/10.1063/1.4841135]
\end{abstract}

\section{INTRODUCTION}

The high power and plasma density associated with cathodic arc results in elevated ion charge states $(Q)$ and inherent ion energies $\left(E_{0}\right)$ ranging up to $>150 \mathrm{eV}^{1,2}$ This corresponds to supersonic ion velocities with respect to the ion sound velocity. ${ }^{3-5}$ Both $Q$ and $E_{0}$ are important in plasma processing as the kinetic ion energy $E$ is given by $E=E_{0}+Q \cdot \Delta U$, where $\Delta U$ is the potential difference between the plasma and the substrate. It is well known that the ion energy affects the film structure and composition and, hence, the film properties.

It has been shown that the inherent ion energy in the plasma near the cathode spots does not depend on the ion charge state. ${ }^{6}$ The suggested explanation presents a gasdynamic mechanism of ion acceleration which is based on pressure gradients and electron-ion coupling. Such gasdynamic mechanisms, especially features of electron-ion coupling and ambipolar diffusion, suggest independence of ion velocity on ion mass in plasma generated from a compound cathode.

We here used DC vacuum arc to study the ion energies/velocities from compound cathodes involving elements of extensively different mass. We found that the most likely ion velocity is independent on mass and, hence, the same for all ion species and ion charge states originating from the same cathode. These results support the prevailing ion acceleration mechanisms suggested in literature ${ }^{6}$ and can aid selection of compound cathodes for thin film synthesis.

\footnotetext{
a) Author to whom correspondence should be addressed. Electronic mail: igozh@ifm.liu.se. Tel.: +46 13 281251. Fax: +46 13137568.
}

\section{EXPERIMENTAL DETAILS}

Charge-state resolved mass spectrometry (Hiden Analytics model EQP) was used to characterize unfiltered DC arc plasma from $63 \mathrm{~mm}$ compound cathodes produced by powder metallurgy. Cathode compositions were selected to include large differences in ion mass, more precisely $\mathrm{Ti}_{0.90} \mathrm{C}_{0.10}, \mathrm{Ti}_{0.90} \mathrm{Si}_{0.10}$, and $\mathrm{Ti}_{0.84} \mathrm{Al}_{0.16}$ cathodes including Ti (48 amu), C (12 amu), Si (28 amu), and Al (27 amu). Also $\mathrm{Ti}, \mathrm{Ti}_{0.95} \mathrm{C}_{0.05}$, and $\mathrm{Ti}_{0.75} \mathrm{C}_{0.25}$ cathodes were studied to see effects from change in relative cathode composition. The arc source was operated at $65 \mathrm{~A}$ arc current at a base pressure around $10^{-6}$ Torr. The front orifice of the spectrometer was placed $33 \mathrm{~cm}$ from the cathode surface, and for each cathode, the plasma was characterized through mass-scans at fixed ion energy and energy-scans at fixed mass-to-charge ratio for all ions. The energy scans were recorded in steps of $0.5 \mathrm{eV} /$ charge up to $200 \mathrm{eV} /$ charge. Each Ion energy distribution (IED) was recorded at least three times to ensure consistency of the data. All values presented are repeatable with a maximum error of $5 \%$. The major isotope was measured for all ions, except for $\mathrm{Ti}^{2+}$, where possible effects from detector saturation on acquired data was excluded by instead selecting the isotope at $23 \mathrm{amu} / \mathrm{charge}$. For further details, see Ref. 7. The electron saturation current and corresponding plasma potential were measured by a Langmuir probe ${ }^{8}$ inserted into the plasma $\sim 2 \mathrm{~cm}$ from, and at the axis of, the EQP orifice. The diameter of the cylindrical probe was $\sim 0.8 \mathrm{~mm}$ with a length of $\sim 1 \mathrm{~mm}$.

\section{RESULTS AND DISCUSSION}

IEDs in the plasma generated from $\mathrm{Ti}_{0.90} \mathrm{C}_{0.10}, \mathrm{Ti}_{0.90} \mathrm{Si}_{0.10}$, and $\mathrm{Ti}_{0.84} \mathrm{Al}_{0.16}$ cathodes are presented in Figure 1 . No 

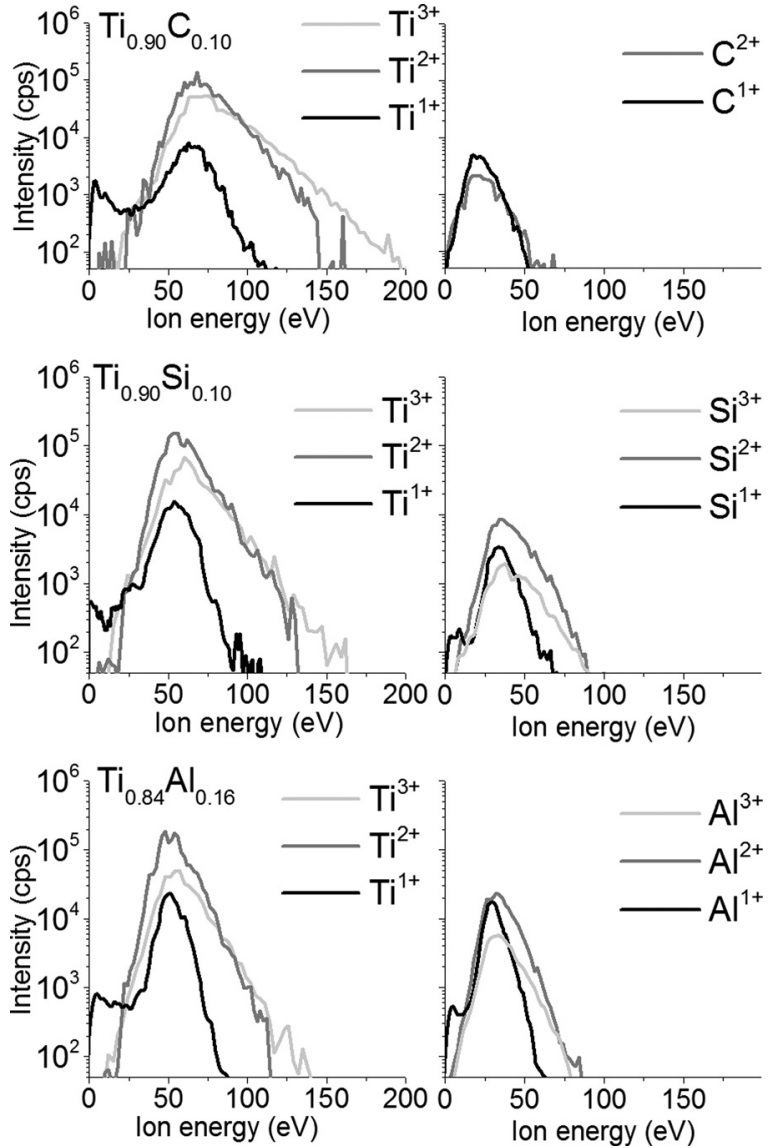

FIG. 1. Ion energy distributions in plasma from $\mathrm{Ti}_{0.90} \mathrm{C}_{0.10}, \mathrm{Ti}_{0.90} \mathrm{Si}_{0.10}$, and $\mathrm{Ti}_{0.84} \mathrm{Al}_{0.16}$ cathodes.

significant intensities were detected for the ions $\mathrm{Ti}^{4+}, \mathrm{Si}^{4+}$, $\mathrm{Al}^{4+}$, and $\mathrm{C}^{3+}$.

The average ion energies were calculated according to

$$
E_{\text {avg }}=\frac{\int I \cdot E \cdot d E}{\int I \cdot d E} .
$$

Table I shows that $E_{a v g}$ for ions of different charge from the same element are typically within $\pm 10 \%$. This correlates

TABLE I. Ion energies in plasmas from $\mathrm{Ti}_{0.90} \mathrm{C}_{0.10}, \mathrm{Ti}_{0.90} \mathrm{Si}_{0.10}$, and $\mathrm{Ti}_{0.84} \mathrm{Al}_{0.16}$ cathodes, based on raw data.

\begin{tabular}{lcccccc}
\hline \hline \multicolumn{7}{c}{$\mathrm{Ti}_{0.90} \mathrm{C}_{0.10}$} \\
\hline Ion & $\mathrm{Ti}^{1+}$ & $\mathrm{Ti}^{2+}$ & $\mathrm{Ti}^{3+}$ & $\mathrm{C}^{1+}$ & $\mathrm{C}^{2+}$ & $\mathrm{C}^{3+}$ \\
$E_{\text {avg }}(\mathrm{eV})$ & 58 & 73 & 80 & 23 & 25 & $\ldots$ \\
$E_{\text {peak }}(\mathrm{eV})$ & 64 & 68 & 72 & 20 & 23 & $\ldots$ \\
& \multicolumn{7}{c}{$\mathrm{Ti}_{0.90} \mathrm{Si}_{0.10}$} \\
& \multicolumn{7}{c}{$\mathrm{Ti}^{1+}$} & $\mathrm{Ti}^{2+}$ & $\mathrm{Ti}^{3+}$ & $\mathrm{Si}^{1+}$ & $\mathrm{Si}^{2+}$ & $\mathrm{Si}^{3+}$ \\
Ion & 53 & 60 & 66 & 35 & 41 & 43 \\
$E_{\text {avg }}(\mathrm{eV})$ & 54 & 57 & 62 & 34 & 36 & 42 \\
$E_{\text {peak }}(\mathrm{eV})$ & & & & & & \\
& & & $\mathrm{Ti}_{0.84} \mathrm{Al}_{0.16}$ & & & \\
\hline Ion & $\mathrm{Ti}^{1+}$ & $\mathrm{Ti}^{2+}$ & $\mathrm{Ti}^{3+}$ & $\mathrm{Al}^{1+}$ & $\mathrm{Al}^{2+}$ & $\mathrm{Al}^{3+}$ \\
$E_{\text {avg }}(\mathrm{eV})$ & 51 & 54 & 58 & 30 & 35 & 37 \\
$E_{\text {peak }}(\mathrm{eV})$ & 50 & 53 & 56 & 29 & 32 & 35 \\
\hline \hline
\end{tabular}

with the energy independence on charge state. ${ }^{6}$ At the same time, the discrepancy between $E_{\text {avg }}$ of different elements is more pronounced.

The most probable energy, $E_{\text {peak }}$, is equal to the IED peak position. It is known that IED can generally be approximated by a shifted Maxwellian distribution. ${ }^{9-11}$ A characteristic feature of the Maxwellian distribution is the high energy tail, which makes $E_{a v g}>E_{\text {peak }}$ (see Table I).

It is evident from Table I that both $E_{\text {peak }}$ and $E_{\text {avg }}$ increase with increasing ion charge state. This fact suggests the presence of an acceleration potential between the plasma and the analyzer. For the present study the analyzer was grounded in all measurements; therefore, it is reasonable to assume that ions were accelerated by the potential difference in the sheath between the plasma and the analyzer orifice. ${ }^{12}$ To determine the plasma potential, it is possible to build a set of equations

$$
\begin{array}{lll}
E_{1}^{(1)}=E_{0}^{(1)}+1 \cdot \Delta U & & E_{1}^{(2)}=E_{0}^{(2)}+1 \cdot \Delta U \\
E_{2}^{(1)}=E_{0}^{(1)}+2 \cdot \Delta U & \text { and } & E_{2}^{(2)}=E_{0}^{(2)}+2 \cdot \Delta U, \\
E_{3}^{(1)}=E_{0}^{(1)}+3 \cdot \Delta U & & E_{2}^{(3)}=E_{0}^{(2)}+3 \cdot \Delta U
\end{array}
$$

where $E_{1}{ }^{(1)}, E_{2}{ }^{(1)}$, and $E_{3}{ }^{(1)}$ are the measured average/peak ion energy for singly, doubly, and triply charged ions of the first cathode element (with corresponding notation for the second cathode element), $E_{0}{ }^{(1)}$ and $E_{0}{ }^{(2)}$ are the initial energies of element 1 and 2 (assumed independent on charge state), and $\Delta U$ is the accelerating potential difference, here equal to the plasma potential.

The set of equations (Eq. (2)) cannot be solved for the average energies $E_{a v g}$ in the Ti-C and Ti-Si plasmas, primarily due to obtained values for single charged ions. The reason can be found in their IEDs (see Figure 1), which have the shortest high energy tails and, at the same time, significant amount of the low energy ions. The latter could be generated during (resonant) charge exchange processes ${ }^{13}$ between singly or multiply charged arc plasma ions and resputtered ${ }^{14,15}$ and/or evaporated ${ }^{16,17}$ atoms of the elements. Instead, an estimation of the plasma potential needs to be based on the results for the peak energies, $E_{\text {peak }}$, in Table I, which according to the equations gives around $+4 \mathrm{~V}$ for the $\mathrm{Ti}-\mathrm{C}$ and $\mathrm{Ti}-$ $\mathrm{Si}$ cathodes and around $+3 \mathrm{~V}$ for the Ti-Al cathode. These values are consistent with here performed Langmuir probe diagnostics (see Figure 2).

Since $E=m \cdot\left(\nu^{2}\right)_{a v g} / 2$ is not equivalent to $E=m \cdot\left(\nu_{\text {avg }}\right)^{2} / 2$, the average energy $\mathrm{E}_{\text {avg }}$ cannot be directly correlated to $\nu_{\text {avg. }}{ }^{18}$ However, for a distinct distribution peak value (the most likely energy or velocity), the correlation between $\nu_{\text {peak }}$ and $E_{\text {peak }}$ is given ${ }^{1,12,18}$ by

$$
\nu_{\text {peak }}=\sqrt{\frac{2 \cdot e \cdot E_{\mathrm{peak}}}{M_{i}}} .
$$

Therefore, a comparison based on peak values of energies and velocities in the plasma have been made (see Table II) after correcting the ion energies by subtracting the energy gained at the analyzer orifice, given by plasma potential times the ion charge state, $Q_{i} \cdot \Delta U$. 


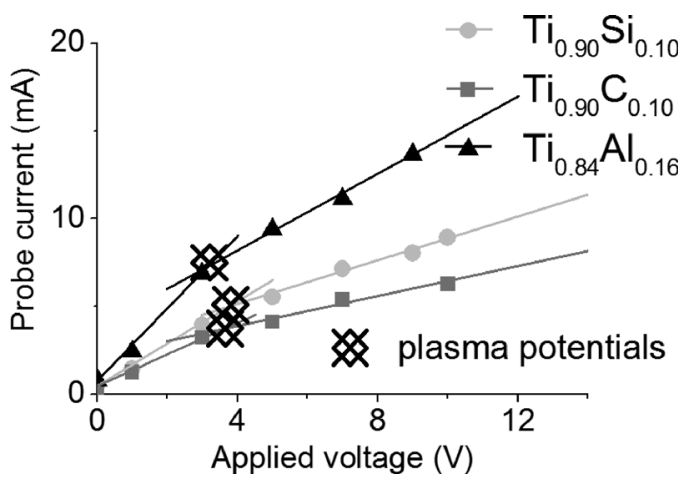

FIG. 2. Langmuir probe results for $\mathrm{Ti}_{0.90} \mathrm{Si}_{0.10}, \mathrm{Ti}_{0.90} \mathrm{C}_{0.10}$, and $\mathrm{Ti}_{0.84} \mathrm{Al}_{0.16}$ cathodes.

From Table II, it is evident that all ions generated from a specific cathode have the same or very similar peak velocities, independent on difference in atomic mass.

The discovered values of ion energies and velocities can be connected with the cohesive energy rule for the elemental cathodes, which establishes a positive correlation between kinetic energies of generated ions and cohesive energy of a cathodic material. ${ }^{17,19}$ The cohesive energies of the present elements are $4.85 \mathrm{eV}(\mathrm{Ti}), 7.37 \mathrm{eV}(\mathrm{C}), 3.39 \mathrm{eV}(\mathrm{Al})$, and $4.63 \mathrm{eV}$ (Si) (see Ref. 2). Therefore, to a first approximation, an addition of carbon into a titanium cathode increases the Ti ion energies (ion velocity) due to increased average cohesive energy for the elements present in the cathode while the addition of $\mathrm{Al}$ correspondingly leads to a decrease. For the $\mathrm{Ti}$-Si cathode, comparable values of the Ti and $\mathrm{Si}$ cohesive energies suggest no significant effect. Peak velocities around 1.37, 1.42 , and $1.55\left(10^{4} \mathrm{~m} / \mathrm{s}\right)$ for $\mathrm{Ti}_{0.84} \mathrm{Al}_{0.16}, \mathrm{Ti}_{0.90} \mathrm{Si}_{0.10}$, and $\mathrm{Ti}_{0.90} \mathrm{C}_{0.10}$ cathodes, respectively, are consistent with the suggested cohesive energy correlation. However, in previous work, ${ }^{7}$ it was shown that there is an increase in ion energies with increasing $\mathrm{Si}$ content in $\mathrm{Ti}-\mathrm{Si}$ cathodes, which was explained by a change in relative quantities of Ti-Si intermetallic compounds with increasing Si content. The calculated cohesive energies of the $\mathrm{Ti}-\mathrm{Si}$ intermetallic compounds are higher than for both pure titanium and silicon, ${ }^{7}$ and therefore

TABLE II. Corrected peak energies, obtained by subtracting $\Delta U \cdot Q_{i}$ from the measured peak energies, and calculated peak velocities in plasmas from $\mathrm{Ti}_{0.90} \mathrm{C}_{0.10}, \mathrm{Ti}_{0.90} \mathrm{Si}_{0.10}$, and $\mathrm{Ti}_{0.84} \mathrm{Al}_{0.16}$ cathodes.

\begin{tabular}{lcccccc}
\hline \hline \multicolumn{7}{c}{$\mathrm{Ti}_{0.90} \mathrm{C}_{0.10} ; \Delta U=\sim 4 \mathrm{eV}$} \\
\hline Ion & $\mathrm{Ti}^{1+}$ & $\mathrm{Ti}^{2+}$ & $\mathrm{Ti}^{3+}$ & $\mathrm{C}^{1+}$ & $\mathrm{C}^{2+}$ & $\mathrm{C}^{3+}$ \\
$E_{\text {peak }}(\mathrm{eV})$ & 60 & 60 & 60 & 16 & 15 & $\ldots$ \\
$\nu_{\text {peak }}\left(10^{4} \mathrm{~m} / \mathrm{s}\right)$ & 1.55 & 1.55 & 1.55 & 1.55 & 1.55 & $\ldots$ \\
\multicolumn{7}{c}{$\mathrm{Ti}_{0.90} \mathrm{Si}_{0.10} ; \Delta U=\sim 4 \mathrm{eV}$} \\
\hline Ion & $\mathrm{Ti}^{1+}$ & $\mathrm{Ti}^{2+}$ & $\mathrm{Ti}^{3+}$ & $\mathrm{Si}^{1+}$ & $\mathrm{Si}^{2+}$ & $\mathrm{Si}^{3+}$ \\
$E_{\text {peak }}(\mathrm{eV})$ & 50 & 49 & 50 & 30 & 28 & 30 \\
$\nu_{\text {peak }}\left(10^{4} \mathrm{~m} / \mathrm{s}\right)$ & 1.42 & 1.40 & 1.42 & 1.44 & 1.38 & 1.44 \\
& \multicolumn{7}{c}{$\mathrm{Ti}_{0.84} \mathrm{Al}_{0.16} ; \Delta U=\sim 3 \mathrm{eV}$} & & \\
\hline Ion & $\mathrm{Ti}^{1+}$ & $\mathrm{Ti}^{2+}$ & $\mathrm{Ti}^{3+}$ & $\mathrm{Al}^{1+}$ & $\mathrm{Al}^{2+}$ & $\mathrm{Al}^{3+}$ \\
$E_{\text {peak }}(\mathrm{eV})$ & 47 & 47 & 47 & 26 & 26 & 26 \\
$\nu_{\text {peak }}\left(10^{4} \mathrm{~m} / \mathrm{s}\right)$ & 1.37 & 1.37 & 1.37 & 1.36 & 1.36 & 1.36 \\
\hline \hline
\end{tabular}

TABLE III. Ion energies in plasmas from $\mathrm{Ti}, \mathrm{Ti}_{0.95}, \mathrm{C}_{0.05}$, and $\mathrm{Ti}_{0.75} \mathrm{C}_{0.25}$ cathodes based on raw data.

\begin{tabular}{|c|c|c|c|c|c|c|}
\hline \multicolumn{7}{|c|}{$\mathrm{Ti}_{100}$} \\
\hline & $\mathrm{Ti}^{1+}$ & $\mathrm{Ti}^{2+}$ & $\mathrm{Ti}^{3+}$ & $\mathrm{C}^{1+}$ & $\mathrm{C}^{2+}$ & $\mathrm{C}^{3+}$ \\
\hline$E_{\text {avg }}(\mathrm{eV})$ & 54 & 61 & 66 & $\ldots$ & $\ldots$ & $\ldots$ \\
\hline$E_{\text {peak }}(\mathrm{eV})$ & 56 & 58 & 60 & $\ldots$ & $\ldots$ & $\ldots$ \\
\hline \multicolumn{7}{|c|}{$\mathrm{Ti}_{0.95} \mathrm{C}_{0.05}$} \\
\hline$E_{a v g}(\mathrm{eV})$ & 55 & 64 & 70 & 20 & 24 & $\ldots$ \\
\hline$E_{\text {peak }}(\mathrm{eV})$ & 55 & 58 & 61 & 17 & 20 & $\ldots$ \\
\hline \multicolumn{7}{|c|}{$\mathrm{Ti}_{0.90} \mathrm{C}_{0.25}$} \\
\hline$E_{a v g}(\mathrm{eV})$ & 69 & 92 & 102 & 29 & 34 & $\ldots$ \\
\hline$E_{\text {peak }}(\mathrm{eV})$ & 82 & 87 & 92 & 24 & 29 & $\ldots$ \\
\hline
\end{tabular}

increasing the proportion of those compounds increases the average cohesive energy of the cathode, and in turn the kinetic ion energy. Corresponding analysis for the Ti-C and the $\mathrm{Ti}-\mathrm{Al}$ systems do not change the qualitative explanation of Table II above. Calculations of the cohesive energy in line with Ref. 7 shows an almost linear decrease in cohesive energy with decreasing $\mathrm{C}$ content for the possible $\mathrm{C}$ (7.8 eV/atom), $\mathrm{TiC}, \quad \mathrm{TiC}_{0.875}, \quad \mathrm{TiC}_{0.75}, \quad \mathrm{Ti}_{2} \mathrm{C}, \quad$ and $\mathrm{Ti}$ (5.3 eV/atom) cathode phases. Similarly, a close to linear increase in cohesive energy with increasing $\mathrm{Ti}$ content is found for the potential $\mathrm{Al}\left(3.4 \mathrm{eV} /\right.$ atom), $\mathrm{TiAl}_{3}, \mathrm{TiAl}_{2}, \mathrm{TiAl}$, $\mathrm{Ti}_{3} \mathrm{Al}$, and Ti phases.

To investigate the effect of relative cathode composition on the kinetic energy/velocity, Ti-C cathodes with a $\mathrm{C}$ concentration of 0,5 , and 25 at. \% were studied (see Tables III and IV). Solving the set of equations (Eq. (2)) for the measured peak energies in plasma from the $\mathrm{Ti}, \mathrm{Ti}_{0.95} \mathrm{C}_{0.05}$, and the $\mathrm{Ti}_{0.75} \mathrm{C}_{0.25}$ cathodes result in an estimated plasma potential around 2,3 , and $5 \mathrm{eV}$, respectively. Langmuir probe measurements confirmed this increasing trend in plasma potential with increased carbon concentration in the cathodes.

Tables III and IV demonstrate increased peak energies and velocities with increased atomic proportion of carbon. As previously mentioned, addition of carbon into a titanium cathode increases the cohesive energy of the cathodic material,

TABLE IV. Corrected peak energies, obtained by subtracting $\Delta U \cdot Q_{i}$ from the measured peak energies, and calculated peak velocities in plasmas from $\mathrm{Ti}, \mathrm{Ti}_{0.95} \mathrm{C}_{0.05}$, and $\mathrm{Ti}_{0.75} \mathrm{C}_{0.25}$ cathodes.

\begin{tabular}{lcccccc}
\hline \hline \multicolumn{7}{c}{$\mathrm{Ti} ; \Delta U=\sim 2 \mathrm{eV}$} \\
\hline Ion & $\mathrm{Ti}^{1+}$ & $\mathrm{Ti}^{2+}$ & $\mathrm{Ti}^{3+}$ & $\mathrm{C}^{1+}$ & $\mathrm{C}^{2+}$ & $\mathrm{C}^{3+}$ \\
$E_{\text {peak }}(\mathrm{eV})$ & 54 & 54 & 54 & $\ldots$ & $\ldots$ & $\ldots$ \\
$\nu_{\text {peak }}\left(10^{4} \mathrm{~m} / \mathrm{s}\right)$ & 1.47 & 1.47 & 1.47 & $\ldots$ & $\ldots$ & $\ldots$ \\
\multicolumn{7}{c}{$\mathrm{Ti}_{0.95} \mathrm{C}_{0.05} ; \Delta U=\sim 3 \mathrm{eV}$} \\
\hline$E_{\text {peak }}(\mathrm{eV})$ & 52 & 52 & 52 & 14 & 14 & $\ldots$ \\
$\nu_{\text {peak }}\left(10^{4} \mathrm{~m} / \mathrm{s}\right)$ & 1.44 & 1.44 & 1.44 & 1.50 & 1.50 & $\ldots$ \\
& \multicolumn{7}{c}{$\mathrm{Ti}_{0.75} \mathrm{C}_{0.25} ; \Delta U=\sim 4 \mathrm{eV}$} & & \\
\hline$E_{\text {peak }}(\mathrm{eV})$ & 77 & 77 & 77 & 19 & 19 & $\ldots$ \\
$\nu_{\text {peak }}\left(10^{4} \mathrm{~m} / \mathrm{s}\right)$ & 1.76 & 1.76 & 1.76 & 1.75 & 1.75 & $\ldots$ \\
\hline \hline
\end{tabular}


either through presence of pure $\mathrm{C}$ or through any Ti-C phase formed. Hence, the here presented results support the cohesive energy rule for compound cathodes suggested in Ref. 7.

The importance of distinguishing between energy and velocity is evident when comparing plasma from pure Ti and $\mathrm{C}$ cathodes. It has been shown that the ion energy is higher for $\mathrm{Ti}$ than $\mathrm{C}^{2}{ }^{2}$ which is one example where the cohesive energy rule for elemental cathodes is not applicable if analyzing kinetic energy only. However, calculating the corresponding ion velocity, the $\mathrm{C}$ ions are found to be faster than the Ti ions, with velocities of 17300 and $15400 \mathrm{~m} / \mathrm{s}$, respectively. ${ }^{2}$ This is consistent with a higher cohesive energy of $\mathrm{C}$ compared to $\mathrm{Ti}$, and with the "frozen" plasma density being higher for $\mathrm{C},{ }^{17,20}$ in turn resulting in higher pressure induced velocity. Therefore, it is reasonable to assume that the addition of carbon into Ti cathodes may increase pressure at the arc spot and, due to that, velocity of all generated ions.

The equality of ion velocities in plasma generated from a compound cathode for such different compositions as Ti$\mathrm{Al}$, Ti-Si, and Ti-C, demonstrates an independence of the velocity on ion mass $M_{i}$ in plasma from one compound cathode material. This result reveals a fundamental feature of plasma generation by vacuum arc which could be written for any two ion species of two compound cathode elements as

$$
\frac{E_{\text {peak } 2}}{E_{\text {peak } 1}}=\frac{M_{2}}{M_{1}} .
$$

Still, unsymmetrical ion energy distributions, especially with discrepancy in the high energy tail (see Figure 1) and possible angular differences in ion velocities (as reported for the plasma composition ${ }^{21}$ ), motivate further experiments to describe the fundamentals of ion velocity in arc plasma generated from compound cathodes.

Since multi-element materials are often synthesized from compound cathodes and the ion energy (velocity) is known to be crucial for the structural evolution of the film, an accurate description of the plasma generation and resulting plasma properties is useful for applications of arc deposition, in particular if utilizing a bias voltage to the substrate.

\section{CONCLUSION}

In conclusion, we have showed that the peak velocities of ions in plasma generated from a compound cathode are equal across elements and charge states and do not depend on ion mass. This can be explained by a gas-dynamic mechanism of ion acceleration based on pressure gradients. The differences in ion velocity between plasma from different compound cathodes are consistent with the cohesive energy rule, suggesting higher ion energies (velocities) from cathodes of higher cohesive energy.

\section{ACKNOWLEDGMENTS}

This work was funded by the European Research Council under the European Community's Seventh Framework Programme (FP7/2007-2013)/ERC Grant Agreement No. 258509). J.R. acknowledges funding from the KAW Fellowship program.

${ }^{1}$ E. Byon and A. Anders, J. Appl. Phys. 93, 1899 (2003).

${ }^{2}$ A. Anders and G. Y. Yushkov, J. Appl. Phys. 91, 4824 (2002).

${ }^{3}$ I. A. Krinberg, Tech. Phys. 46(11), 1371-1378 (2001).

${ }^{4}$ G. Yushkov, A. Bugaev, I. Krinberg, and E. Oks, Dokl. Phys. 46(5), 307-309 (2001)

${ }^{5}$ G. Yushkov, A. Anders, E. Oks, and I. Brown, J. Appl. Phys. 88(10), 5618 (2000).

${ }^{6}$ A. Anders and E. Oks, Cathodic Vacuum Arcs: Do the Ion Velocity Distribution Functions Depend on the Ion Charge State? (Lawrence Berkeley National Laboratory, 2006).

${ }^{7}$ A. Eriksson, I. Zhirkov, M. Dahlqvist, J. Jensen, L. Hultman, and J. Rosén, J. Appl. Phys. 113(16), 163304 (2013).

${ }^{8}$ N. Herskowitz, "How Langmuir probes work," in Plasma Diagnostics, edited by O. Auciello and D. L. Flamm (Academic Press, Inc., San Diego, 1989).

9 J. Rosén, A. Anders, S. Mráz, and J. Schneider, J. Appl. Phys. 97, 103306 (2005).

${ }^{10}$ M. M. M. Bilek, P. J. Martin, and D. R. McKenzie, J. Appl. Phys. 83(6), 2965 (1998).

${ }^{11}$ J. Rosén, A. Anders, S. Mráz, A. Atiser, and S. Jochen, J. Appl. Phys. 99, 123303 (2006).

${ }^{12}$ A. Anders and E. Oks, J. Appl. Phys. 101, 043304 (2007).

${ }^{13}$ B. Smirnov, Usp. Fiz. Nauk 171, 233-266 (2001).

${ }^{14}$ A. Anders, Appl. Phys. Lett. 85, 6137-6139 (2004).

${ }^{15}$ A. Anders, IEEE Trans. Plasma Sci. 33, 205-209 (2005).

${ }^{16}$ G. Lins, IEEE Trans. Plasma Sci. 15, 552-556 (1987).

${ }^{17}$ A. Anders, Cathodic Arcs. From Fractal Spots to Energetic Condensation, 1st ed. (Springer, New York, 2008).

${ }^{18}$ J. Rosén, J. Schneider, and A. Anders, Appl. Phys. Lett. 89, 141502 (2006).

${ }^{19}$ A. Anders, "The evolution of ion charge states in cathodic vacuum arc plasmas: A review," Plasma Sources Sci. Technol. 21, 035014 (2012).

${ }^{20}$ A. Anders, Phys. Rev. E 55, 969-981 (1997).

${ }^{21}$ A. G. Nikolaev, G. Yu. Yushkov, K. P. Savkin, and E. M. Oks, Rev. Sci. Instrum. 83, 02A503 (2012) 